\title{
Low awareness about CADTH among practising doctors in Canada
}

\author{
n Cite as: CMAJ 2018 May 7;190:E576. doi: 10.1503/cmaj.109-5595
}

Posted on cmajnews.com on Apr. 18, 2018.

W hen you invite prominent local clinicians to your annual conference and they have to Google you to find out what you do, it suggests an image problem, particularly if you are the Canadian Agency for Drugs and Technology in Health (CADTH).

Although acknowledged as an international leader in reviewing the efficacy and cost-effectiveness of new drugs and technologies, CADTH struggles for recognition among physicians not involved in its programs. At the agency's annual meeting in Halifax, Dr. Brian O'Rourke, its CEO and president, acknowledged the problem and said they are taking steps to engage more clinicians.

The opening plenary panel discussion - featuring deputy ministers of health from Nova Scotia, Alberta, and Newfoundland and Labrador - touched on many issues of relevance to physicians, including the shortage of family doctors in Nova Scotia and the contribution of prescribing practices to the opioid crisis. In contrast, the opening panel at the annual meeting two years ago featured only clinicians and dealt specifically with how evidence affects practice.

This year, practising physicians comprised a small minority of delegates or speakers in plenary or workshop sessions. Doctors attending the meeting said they weren't surprised by the low awareness about CADTH among their colleagues.

Dr. Gigi Osler, president-elect of the Canadian Medical Association, said she feels many "hardworking doctors in practice" may not have heard of CADTH. "I am overwhelmed at the importance of this meeting," she said. "To be in a room where you have the policy-makers, you have assistant deputy ministers and deputy ministers

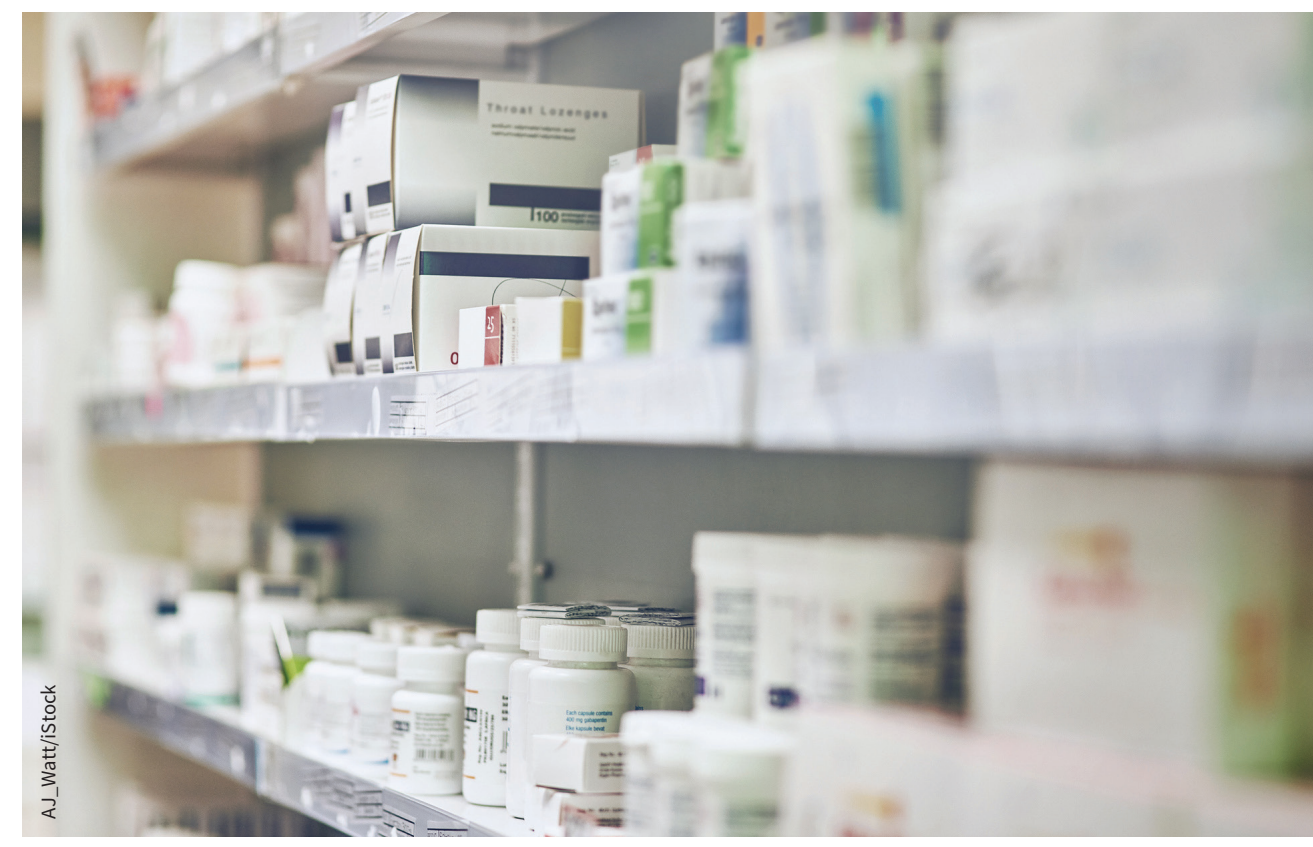

CADTH is recognized as an international leader in reviewing the efficacy and cost-effectiveness of new drugs.

along with the researchers and the academics. I am surprised more front-line practitioners and medical associations aren't here."

Dr. Allan Grill, the provincial medical lead of primary care for the Ontario Renal Network, said he became aware of CADTH only through his involvement with health technology assessment (HTA) committees focusing on publicly funded drug formularies. "The CADTH HTA reports have a lot of valuable information on new drug products, but knowledge translation that targets practising physicians does not seem to be a high priority. CADTH should strongly consider developing more effective dissemination strategies to better support appropriate prescribing in clinical practice."

The agency's new strategic plan has identified strengthening engagement with clinicians as an important part of closing the gap between evidence, policy and practice. "We will convene forums for clinicians to engage with experts to discuss their own practice patterns and experiences, with a view to creating momentum and strategies for improvement," states the report.

"We want to be a much better support to the practice community," said O'Rourke, noting that about 18 months ago CADTH created a clinician-engagement strategy. One of the first steps was to hire a practising physician to head its medical devices and clinical interventions section. O'Rourke also talked about reaching out to medical associations "to better support the evidence needs of physicians" as well as to offer continuing medical education.

Pat Rich, Ottawa, Ont. 